\title{
PERI-IMPLANT STRAINS WITH PALATELESS LOCATOR RETAINED MAXILLARY IMPLANT OVERDENTURES REINFORCED WITH EITHER METAL OR POLY ETHER-ETHER KETONE (PEEK) MATERIALS. AN INVITRO STUDY
}

\author{
Sahar A. Kortam*
}

\begin{abstract}
Objectives: The purpose of the present report was to assess, using strain gauge analysis, the peri-implant strains with palateless locator retained maxillary implant overdentures reinforced with either cobalt chromium metal or Poly ether-ether ketone (PEEK) materials.

Material and methods: Four implants were installed in completely edentulous acrylic maxillary cast in canine and second premolar region and mucosal simulation was added. Two strain gauges were bonded at buccal and palatal surface of each implant. Ten experimental palateless maxillary overdentures, 5 with cobalt chromium metal reinforcement (group I) and other 5 with PEEK reinforcement (group II) were fabricated and connected to the implants with Locator attachments (Light retention). Strain was measured at canine and premolar implants during application of axial static load of $100 \mathrm{~N}$ in bilateral and unilateral direction.
\end{abstract}

Results: For, canine and premolar implants during bilateral and unilateral load application, the median strains of metal reinforcement were significantly higher than median strains of PEEK reinforcement. For metal reinforcement group (during bilateral and unilateral loading), and PEEK reinforcement (during unilateral loading) premolar implant showed significant higher strain than canine implants. Premolar implants for metal reinforcement showed significant higher strain during unilateral loading compared to bilateral loading.

Conclusion: Within restrictions of this invitro study, PEEK reinforcement is recommended than metal cobalt chromium reinforcement for palateless maxillary implant overdentures from biomechanical point of view as it achieved low peri-implant strains during unilateral and bilateral loading

\footnotetext{
* Lecturer of Removable Prosthodontics, Faculty of Dentistry, Beni-Seuf University.
} 


\section{INTRODUCTION}

Implant supported maxillary overdenture can provide increased retention, stability, good speech, appearance, lip support and oral hygiene which is often not possible with a fixed maxillary prosthesis ${ }^{1}$. Compared to fixed restoration implant overdenture in maxilla are indicated with increased inter maxillary distance to avoid long prosthetic teeth, when insufficient bone volume presents, when cost is a factor as overdentures usually require fewer implants, and in subjects with complex skeletal conditions such as class III ${ }^{2}$. Sadowsky ${ }^{3}$ stated that four implants were the minimum number of implants that should retain a maxillary overdenture and recommended six implants with compromised bone. The horseshoe (palateless) design of the maxillary overdenture is well-accepted by the patients due to greater comfort resulted from reduction of tissue coverage in contrast to complete palatal coverage ${ }^{4}$. Removal of the palate also improves maintenance of oral sensation and function ${ }^{5}$, indicated for subjects with a gagging reflex, psychologic disturbance, or if torus palatinus exists ${ }^{4}$. However, palatal coverage for a maxillary overdenture were shown to reduce load transfer to supporting implants and distribute stress between implants and adjacent soft tissue than palateless designs ${ }^{4}$. In addition, palateless overdentures are more deformable than dentures with palatal coverage ${ }^{6}$.

Implant-supported overdentures used several retention systems that may be splinted or unsplinted. The splinted attachments are the bar attachments while the unsplinted (solitary) include ball attachment, magnets, telescopic crowns or stud-type (locator) attachments ${ }^{7}$. When used for maxillary overdentures, the solitary attachments can be used with reduced horizontal and vertical space compared to bar structures. This reduce denture bulkiness and enhance esthetics and phonetics. Unsplinted attachments also are simple, cost effective and are associated with simplified hygienic procedures compared to bars ${ }^{8}$. One of the most commonly used unsplinted attachments nowadays is resilient stud attachments (Locators). Such anchors have double retentive forces, and different color inserts according to retention values. The decreased height of the Locators reduced restorative space to avoid denture deformation and fracture 9. Moreover, resilient studs have inserts that can be used with angulated implants $20^{\circ}$ 10-12.

Denture deformation may cause various prosthetic problems as denture fracture, tooth dislodgement, loosening of attachments or biological problems as mucosal ulceration, ridge resorption, implant overload and implant loss. The increased occlusal stresses could lead to bone resorption and osseointegration loss of the implant. With increased load, micromotions are transmitted through the implant to the bone with high stress concentration in the crestal portion of the implant. Reinforcement of the maxillary implant overdenture was reported to decrease stress around implants with complete and partial palatal coverage regardless of the implant distribution ${ }^{13}$. The authors added that reinforcement improve the rigidity of the denture base and minimize base deformation, distribute functional forces equally to the implants regardless of overdenture type. ${ }^{13}$

In a recent systematic review ${ }^{14}$, several studies reported reinforcements of the denture base with metallic (cobalt chromium) and non-metallic (such as polyethylene, polyaramid, and glass fibers). Materials other than metal for denture reinforcing were tested to avoid heavy weight of metals, bad appearance and reduced adhesion of metal to acrylic resin of the dentures ${ }^{15}$. Poly ether-ether ketone (PEEK) is a high-performance polymer which can be utilized as a metal substitute for prosthetic restorations. PEEK has high strength to weight ratio, resist corrosion, is biocompatible, not interfere with radiographic evaluation (radiolucent), has low plaque liability as well as chemical stability ${ }^{16-18}$. It also has low creep, high wear resistance and good shock absorbing ability ${ }^{19,20}$. PEEK also has a reduced weight that allow construction of light prosthesis to increase patient satisfaction and comfort in function ${ }^{21}$. The PEEK 
material can be constructed by either computer aided design/computer aided manufacturing (CAD/ CAM) or by injection molding ${ }^{21}$

The purpose of this investigation was to assess peri-implant strains with palateless locator retained maxillary implant overdentures reinforced with either metal or Poly ether-ether ketone (PEEK). The proposed null hypothesis is lack of significant difference in strains around implants between both types of denture reinforcement

\section{MATERIALS AND METHODS}

\section{Construction of experimental model}

A complete edentulous maxillary model was constructed using heat polymerized acrylic resin (Acroston, Egypt). Acrylic resin trial denture base with complete arrangement of artificial teeth was constructed over a stone duplicate of the acrylic model. The denture was processed with clear heat cure resin to be used as a guide in implant installation. The template was used as a guide for marking implant placement sites (canines and second premolars) bilaterally using a parallometer milling machine (Milling unit BF 2, Bredent, GmbH\&Co, $\mathrm{KG}$, German). Twist drills of successive sizes were connected to the milling device and utilized to make four depressions through the guide template. Four laboratory implants (TioLogic, Dentaururm, Ispringen, Germany, $4.2 \times 12 \mathrm{~mm}$ ) were attached in the canine and second premolar areas bilaterally using auto-polymerized acrylic resin to simulate osseointegriation $^{22}$. The remaining ridge and the palate of acrylic resin model were covered with 1.5 $\mathrm{mm}$ thickness of resilient liner material to simulate oral mucosa $a^{23}$. Four Locator abutments (Female component, medium, mucosal height $=3 \mathrm{~mm}$ ) were threaded to the fixtures using $20 \mathrm{Ncm}$ torque wrench (fig 1). Locator housings with processing caps were snapped on the abutments and the cast was duplicated and poured with stone.

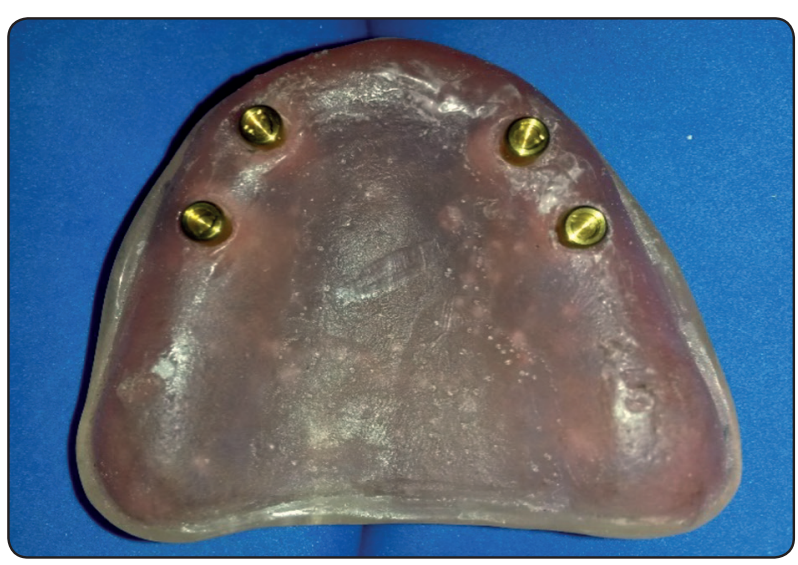

Fig. (1) The experimental model

\section{Construction of the reinforcement framework}

The model was scanned using CAD/CAM device (Ceramill Map400, Amann Girrbach AG. Koblach, Austria). Using the software of the device, the reinforcement frame was designed with a 1.0 $\mathrm{mm}$-thickness to cover the crest of the ridge and the attachment after providing adequate space for pick up of the locator housing and saved as STL file. The designed frame was either printed (using additive method) in castable resin using a laser sintering device (EOSINT, Germany) (group I) or milled in PEEK blocks using CAD/CAM subtractive manufacturing (group II). For Group I, five castable resin frames (GC Pattern Resin, GC Corp, Tokyo, Japan) were invested, cast in cobalt chromium metal (Fig 2a). For group II, five frames were milled in modified PEEK discs (BioHPP, high performance polymer, Bredent $\mathrm{GmbH} \& \mathrm{Co} . \mathrm{KG}$, Weißenhorner Str. 2, 89250 Senden, Germany) (fig 2b).The thickness of both metal and PEEK frames was standardized at $1 \mathrm{~mm}^{24}$

\section{Construction of experimental overdentures}

The acrylic model was duplicated into 10 stone models (one model for each reinforcement frame) using silicone duplicating material. The reinforcement frames were placed over the models (metal frames were used for 5 models and PEEK frames were used for 5 models). Ten maxillary 


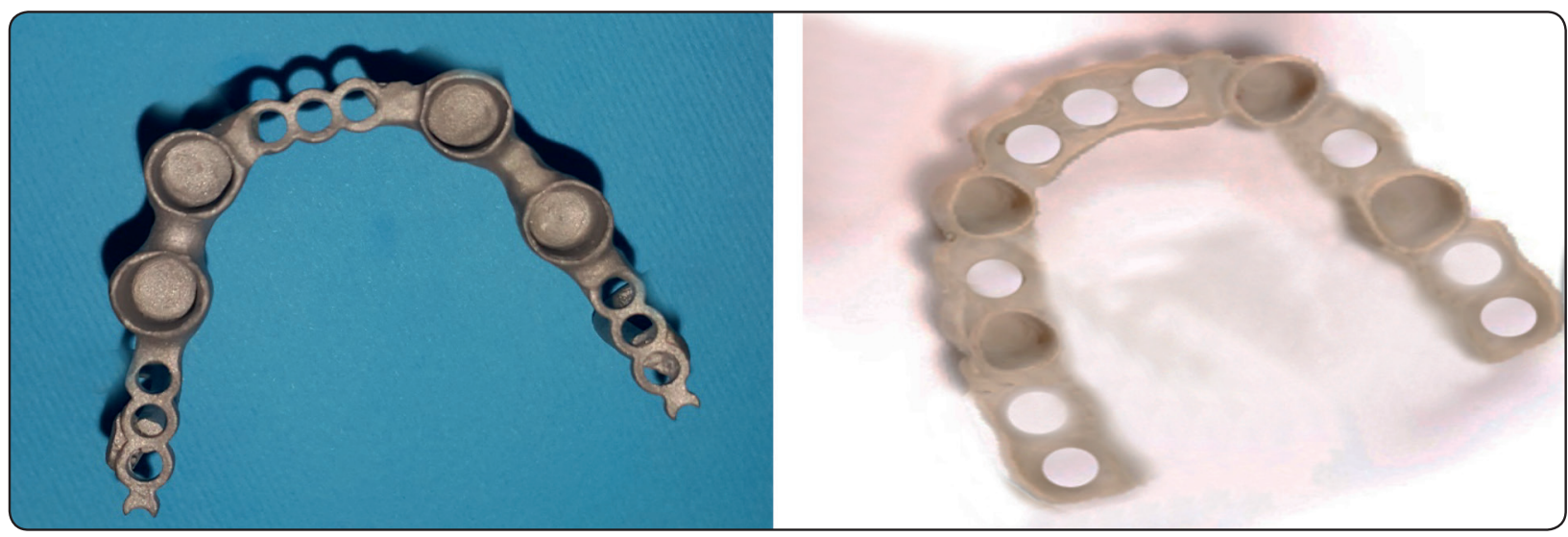

Fig. (2) Reinforcement frames A; metal reinforcement (group I), B; PEEK reinforcement (group II)

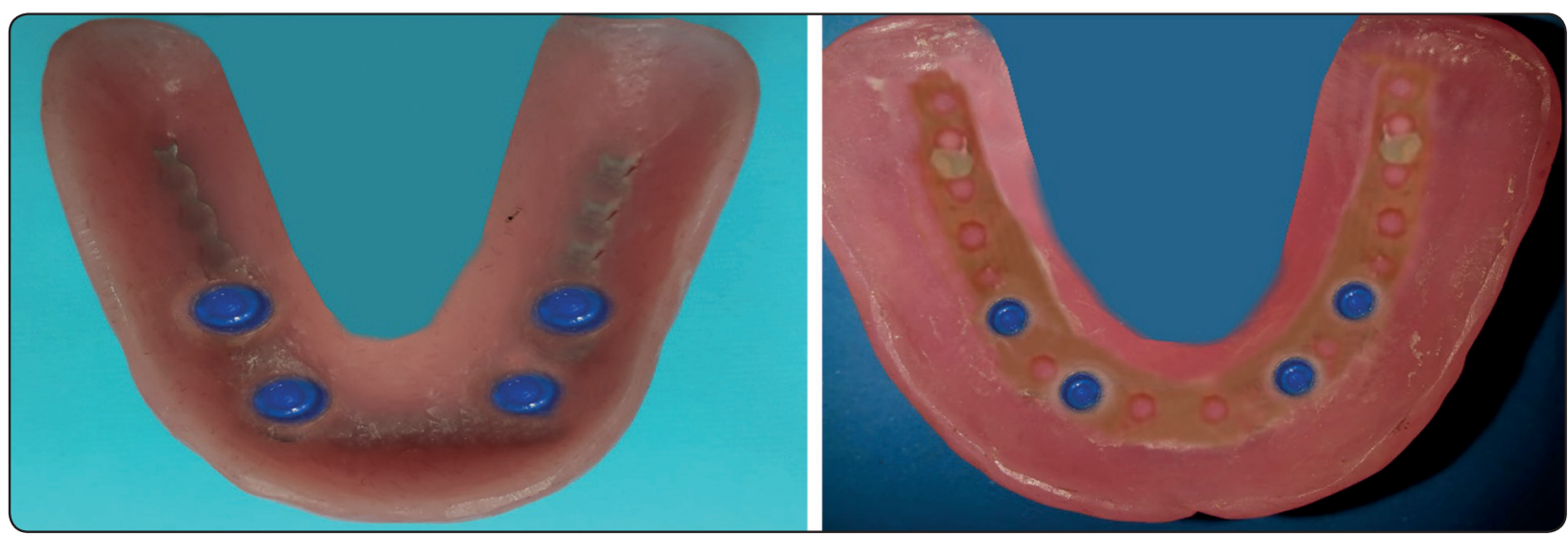

Fig. (3) Reinforced experimental overdentures; A, metal reinforced palateless overdenture (group I), B; PEEK reinforced palateless overdenture (group II)

experimental overdentures ( 5 for each group) were fabricated and attached to the implants with Locator attachments. This sample size was selected based on power analysis conducted using finding of a previous study in which the authors used a similar study design ${ }^{25}$ to yield a $95 \%$ power (effect size $=3.01, \alpha$ two-tailed $=.05$ ). Each experimental denture consisted of denture base and occlusion rim. A wax occlusion rim was constructed without any denture teeth with occlusal plane parallel to the crest of the ridge ${ }^{26}$. The denture base was constructed with partial palatal coverage (horse shoe design). The dentures were flasked, reinforcement frames were positioned over the casts, and packing of heat-cured acrylic resin over the frames were completed. On the acrylic model, each experimental overdenture was attached to the locator matrices using self-cure acrylic resin. Processing caps were changed with blue inserts (light retentive forces) (fig 3)

\section{Peri-implant strain measurement}

The silicone resilient material was removed from the buccal and palatal aspect of each implant. Two strain gauges (Kyowa electronic instrument co.,LTD Tokyo, Japan) were adhered to the surface of acrylic resin at buccal and palatal aspects of each fixture after preparation of acrylic surface to be flat. The right is considered loading side and left is the non-loading one (fig 4). The long axes of the gauges were oriented parallel to the long axes of 


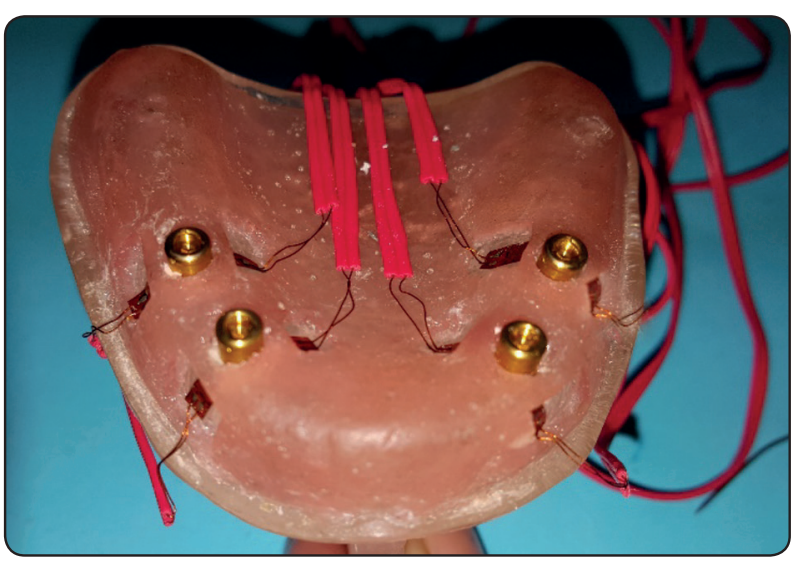

Fig. (4) Strain gauge positions on the cast

the implants. All gauges were luted with special adhesion material (Kyowa Electronic Instrument).

The gauge wires were secured to the cast with bonding adhesion material to avoid any wire displacement that lead to inaccurate readings. The wires were attached to a strain meter with 8 channels (Tinsley) that attached to a personal computer containing a software (Kywa PCD). A $1 / 4$ bridge circuit was utilized. A loading device was used to deliver axial static force (unilateral and bilateral). During bilateral load application (fig 5a), forces were delivered to the centre of a metal bar that was positioned over the rim at frits molar area. During unilateral load application (fig 5b), load was delivered in central occlusal fossa of the 1 st molar $^{27}$,
28. Vertical load of $100 \mathrm{~N}$ was applied at a constant rate of $0.5 \mathrm{~mm} \backslash \mathrm{min}$. The data were detected as $\mu$ volts and converted to $\mu$ Strain (microstrain). Absolute values of buccal and palatal strains were averaged and the mean was subjected to statistical analysis. During bilateral loading, right and left canine and premolar implants strain were averaged and the average was used in statistics. During unilateral loading the right canine and premolar implant readings were used.

\section{Statistical analysis}

Shapiro-Wilk test utilized used to identify the normality of data. Mann Whitney test was used to compare recorded microstrain values between groups (metal and PEEK reinforcements), and implant positions (canine and premolar implants). Wilcoxon signed ranks test was used to compare bilateral and unilateral loading. $\mathrm{P}$ value is significant at .05 level.

\section{RESULTS}

The data were not parametric, did not normally distributed and expressed by median, minimum and maximum. Comparison of registered micro-strain between the tested groups as well as between canine and premolar implants during bilateral loading is presented in table 1 . For, canine and premolar implant during bilateral loading, the median strains

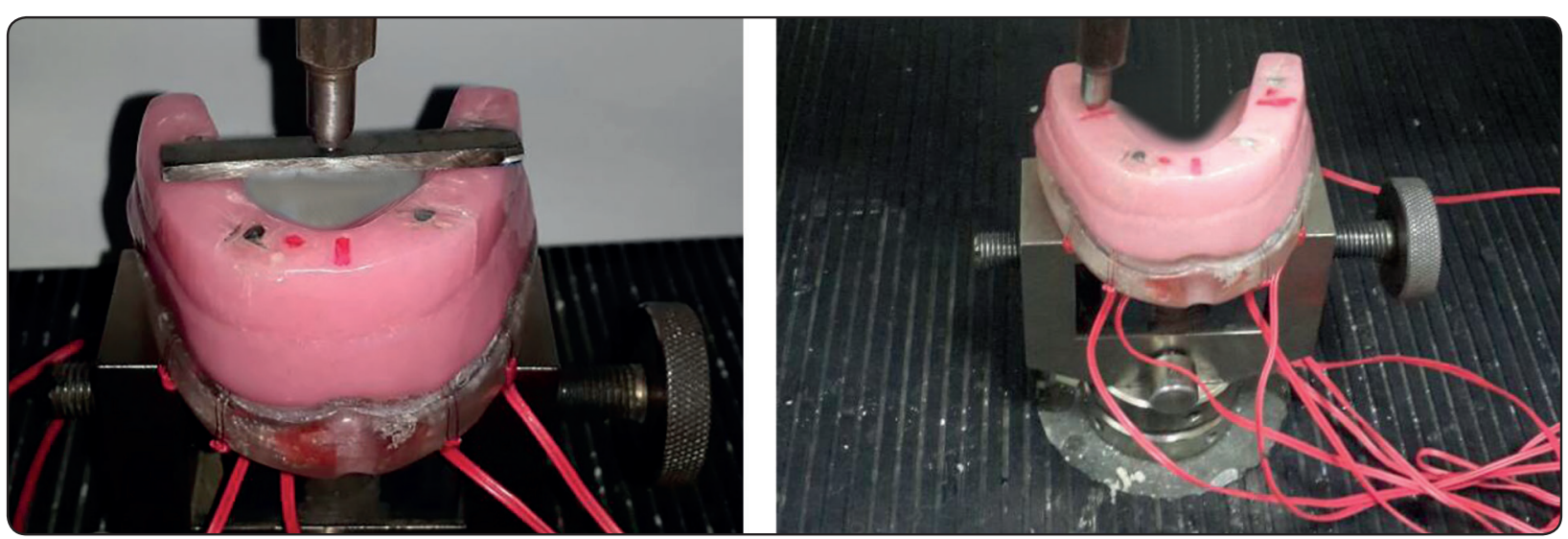

Fig. (5) A; bilateral load application, B; Unilateral load application 
of metal reinforcement were significantly higher than median strains of PEEK reinforcement $(\mathrm{P}=.001$ and <.001) for canine and premolar implants respectively. The same table showed comparison between implant positions. For metal reinforcement group, premolar implant showed significant higher strain than canine implants $(\mathrm{p}=.016)$. However, for PEEK reinforcement group, no difference in strain of canine and premolar fixtures was noted.

Comparison of registered microstrain between groups and between canine and premolar implants during unilateral loading is presented in table 2 . For, canine and premolar implant during unilateral loading, the median strains of metal reinforcement were significantly higher than median strains of PEEK reinforcement $(\mathrm{P}=.002$ and <.003) for canine and premolar implants respectively.
The same table showed comparison between implant positions. For metal reinforcement group, premolar implant showed significant higher strain than canine implants $(\mathrm{p}=.007)$. Also, for PEEK reinforcement group, premolar implant showed significant higher strain than canine implants $(\mathrm{p}=.001)$.

Comparison of registered strains between unilateral and bilateral loading for both groups and implant positions are presented in fig 6. Canine implants for both groups showed no significant difference in stain between bilateral and unilateral loading. Premolar implants for metal reinforcement showed significant higher strain during unilateral loading compared to bilateral loading $(\mathrm{p}<.001)$. However, premolar implants for PEEK reinforcement showed no significant difference in stain between bilateral and unilateral loading.

TABLE (1) Registered microstrain of groups and implant positions (canine and premolar implants) during bilateral loading

\begin{tabular}{|c|c|c|c|c|c|c|c|}
\hline & \multicolumn{3}{|c|}{ Canine implants } & \multicolumn{3}{|c|}{ Premolar implants } & \multirow{2}{*}{$\begin{array}{c}\text { Mann Whitney test } \\
\text { (p value) }\end{array}$} \\
\hline & Me & Mini & Maxi & Me & Mini & Maxi & \\
\hline Metal reinforcement & 55.00 & 40.00 & 80.00 & 72.50 & 50.00 & 100.00 & $.016^{*}$ \\
\hline PEEK reinforcement & 43.50 & 35.00 & 55.00 & 45.00 & 35.00 & 70.00 & $.43 *$ \\
\hline Mann Whitney test ( $\mathrm{p}$ value) & \multicolumn{3}{|c|}{$.001 *$} & \multicolumn{3}{|c|}{$<.001 *$} & \\
\hline
\end{tabular}

Me; median, Mini; minimum,

Maxi; maximum, * p is significant at $5 \%$ level

TABLE (2) Registered microstrain of groups and implant positions (canine and premolar implants) during unilateral loading

\begin{tabular}{|l|c|c|c|c|c|c|c|}
\hline \multicolumn{7}{|c|}{ Canine implants } & \multicolumn{7}{c|}{$\begin{array}{c}\text { Mann Whitney test } \\
(\mathrm{p} \text { value })\end{array}$} \\
\hline & Me & Mini & Maxi & Me & Mini & Maxi & \\
\hline Metal reinforcement & 57.50 & 35.00 & 175.00 & 170.00 & 35.00 & 200.00 & $.007 *$ \\
\hline PEEK reinforcement & 40.00 & 35.00 & 45.00 & 50.00 & 35.00 & 60.00 & $.001 *$ \\
\hline Mann Whitney test (p value) & & $.002 *$ & & & $.003 *$ & & \\
\hline
\end{tabular}

Me; median, Mini; minimum,

Maxi; maximum, * p is significant at $5 \%$ level 


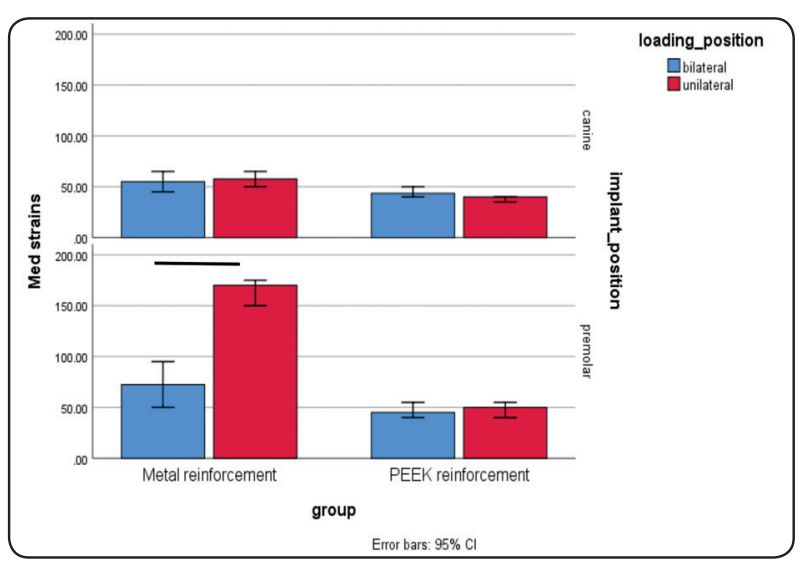

Fig. (6) Comparison of registered microstrain between unilateral and bilateral loading for both groups and implant positions. Line connecting bars indicate significant difference between unilateral and bilateral loading

\section{DISCUSSION}

Record blocks were constructed without denture teeth for measurement as the position of the loading pin over inclined cusps of the posterior teeth will result in slippage of the pin and application of nonaxial loading (oblique, horizontal and lateral) on the occlusal surface of the denture ${ }^{26}$. The same cast was used for all measurements for standardization of strain gauge position as it is impossible to duplicate the strain gauge positions if several casts were used.

The reinforcement frameworks were designed over the abutments and crest of the ridge, as it is more effective in denture strain reduction than just reinforcing side of the denture ${ }^{26}$. It is possible to measure strains at bone surface and used to indicate moment forces ${ }^{29}$. Therefore, the gauges were positioned on the surface of the resin. Two strain gauges were attached to each implant at buccal and lingual aspects only, as there was no enough distance to attach them mesially and distally around the implants inserted in canine and second premolar positions because of the near proximity of the implants to each other. Moreover Takahashi, et al. ${ }^{30}$ found that palate-labial strain on the implant was much higher than mediodistal strains.
A gradual static load was applied (100 Newton) using the universal testing machine. This magnitude was utilized as it falls in the range of occlusal mastication and similar to load exerted by patients wearing implant overdentures 31, 32 . Measurement of strains was made during unilateral loading to simulate chewing on the preferred side of the patient and during bilateral loading to simulate patient closure on denture teeth in centric occlusion. Biomechanical studies have suggested that the main cause of bone resorption is implant overload $^{33-35}$. Although the effect of reinforcement by several materials on denture base deformation and fracture was investigated in several studies $^{6,26,30}$, the influence of type of reinforcement material on the peri-implant strains was not investigated sufficiently.

Overdenture reinforcement can protect the underlying supporting structures ${ }^{36}$. The increased rigidity of the denture causes even load distribution to the implants and residual ridge ${ }^{14}$. The results shown significant higher peri-implant strains with metal reinforcement than with PEEK reinforcement during unilateral and bilateral loading. The reduced periimplant strain with PEEK reinforcement may be attributed to the reduced modulus of elasticity, dampening of the occlusal forces, and shock absorption capability of PEEK frameworks compared to Cr-Co castings ${ }^{19,20}$. Moreover, the BioHPP material used in this study is elastic as bone, which acts as a stress breaker and reduces the occlusal load transmitted to the prosthesis and implants ${ }^{37}$. The increased periimplant strains with cobalt chromium reinforcement was in line with results of Takahashi et al. ${ }^{13}$ who found that strain around implants supporting a palateless maxillary overdenture with metal reinforcing and a palatal bar less than reinforcement without palatal bar. The authors found that although strains were reduced, they are higher than strains with full palatal coverage and metal reinforcement. They added that palatal bar may enhance the rigidity of dentures with partial palatal coverage. dentures with 
partial palatal coverage. However, another study has proved that, excluding the palatal bar (like the design used in this study) showed no difference in strain around implants with bar or individual anchors ${ }^{38}$. In a recent study, Hada et al. ${ }^{24}$ concluded that $\mathrm{CAD} / \mathrm{CAM}$ reinforcement frame is beneficial in reduction of conventional maxillary denture deformation and denture strains. They found that PEEK showed a reduced reinforcement effect than cobalt chromium. However, they measured denture strain not peri-implant strain. From clinical point of view, these results suggests that PEEK reinforcement may prevent implant overload complications (such as peri-implant bone loss, screw lessening and fracture and attachment wear) and remaining alveolar ridge loss by reducing the concentration of load transferred to implants or ridge ${ }^{13}$.

For both groups during bilateral and unilateral loading, premolar implant showed significant higher strain than canine implants. This may be due to the close proximity of premolar implants to the site of load application. Up on loading, the premolar implants act as a fulcrum (due to the cantilever action of the denture base) causing overdenture rocking antroposteriorly which increase strain on premolar implants ${ }^{39}$. Unilateral load application recorded significant higher peri-implant strain than bilateral load application for metal reinforcement group at premolar implants only. This could be attributed to the behavior of maxillary implant overdenture during load application (deformation away from the midline) that is similar to maxillary complete dentures ${ }^{40}$. During unilateral loading, all forces are transmitted to the loading side, while during bilateral loading forces are equally distributed on both sides. A similar finding was also reported in several strain gauge ${ }^{41}$, photoelastic ${ }^{42,43}$ and finite element ${ }^{44}$ investigations.

There is a difference in physical properties of acrylic resins and living bone with respect to mechanic and and biologic properties. Therefore, the results should be approached with caution.
Moreover, axial axial force only was applied and lack of application of non-vertical forces is another limitation of this study as the natural occlusal forces usually complex and composed of a combination of axial, horizontal and oblique forces. Further studies may be helpful to address this issue ${ }^{45}$. Also, future clinical studies are needed to evaluate the effect of both types of denture base reinforcement on clinical implant outcomes such as: peri-implant marginal bone loss, prosthetic complications and satisfaction with palateless maxillary implant overdentures.

\section{CONCLUSION}

Within the restrictions of this invitro study, PEEK reinforcement is recommended than metal cobalt chromium reinforcement for palateless maxillary implant overdentures from biomechanical point of view as it was associated with reduced peri-implant strains during unilateral and bilateral loading.

\section{REFERENCES}

1. Slot W, Raghoebar GM, Vissink A, Huddleston Slater JJ, Meijer HJ. A systematic review of implant-supported maxillary overdentures after a mean observation period of at least 1 year. J Clin Periodontol. 2010;37:98-110.

2. Mericske-Stern RD, Taylor TD, Belser U. Management of the edentulous patient. Clin Oral Implants Res. 2000;11 Suppl 1:108-25.

3. Sadowsky SJ. Treatment considerations for maxillary implant overdentures: a systematic review. J Prosthet Dent. 2007;97:340-8.

4. Ochiai KT, Williams BH, Hojo S, Nishimura R, Caputo AA. Photoelastic analysis of the effect of palatal support on various implant-supported overdenture designs. J Prosthet Dent. 2004;91:421-7.

5. Tanino F, Hayakawa I, Hirano S, Minakuchi S. Finite element analysis of stress-breaking attachments on maxillary implant-retained overdentures. Int J Prosthodont. 2007;20:193-8.

6. Mizuno Y, Takahashi T, Gonda T, Maeda Y. Mechanical analysis of a palateless denture. Int J Prosthodont. 2013; 26:419-22. 
7. Kobayashi M, Srinivasan M, Ammann P, Perriard J, Ohkubo $\mathrm{C}$, Muller F, et al. Effects of in vitro cyclic dislodging on retentive force and removal torque of three overdenture attachment systems. Clin Oral Implants Res. 2014;25:426-34.

8. Cavallaro JS, Jr., Tarnow DP. Unsplinted implants retaining maxillary overdentures with partial palatal coverage: report of 5 consecutive cases. Int J Oral Maxillofac Implants. 2007; 22:808-14.

9. Chandan KS, Agrawat P ,Mistry G , Singh R . Implant Supported Overdenture Attachments- A Review . J of Den. and Med. Sciences .2017; 11: 87-91

10. Stephens GJ, di Vitale N, O'Sullivan E, McDonald A.The influence of interimplant divergence on the retention characteristics of locator attachments, a laboratory study. J Prosthodont. 2014;23:467-75.

11. Jabbour Z, Fromentin O, Lassauzay C, et al: Effect of implant angulation on attachment retention in mandibular two-implant overdentures: a clinical study. Clin Implant Dent Relat Res .2014;16:565-571

12. Schere MD. Managing Angulation Challenges With Implant Overdenture. Compendium J .2019; 40 Issue 1

13. Takahashi T, Gonda T, Maeda Y. Can Reinforcement of Maxillary Implant Overdentures Decrease Stress on Underlying Implants? Int J Oral Maxillofac Implants. 2017;32:63-9.

14. Gibreel MF, Khalifa A, Said MM, Mahanna F, El-Amier $\mathrm{N}$, Narhi TO, et al. Biomechanical aspects of reinforced implant overdentures: A systematic review. J Mech Behav Biomed Mater. 2019;91:202-11.

15. Rached RN, de Souza EM, Dyer SR, Ferracane JL. Dynamic and static strength of an implant-supported overdenture model reinforced with metal and nonmetal strengtheners. J Prosthet Dent. 2011;106:297-304.

16. Hahnel S, Wieser A, Lang R, Rosentritt M. Biofilm formation on the surface of modern implant abutment materials. Clin Oral Implants Res. 2015;26:1297-301.

17. Wang H, Xu M, Zhang W, Kwok DT, Jiang J, Wu Z, et al. Mechanical and biological characteristics of diamond-like carbon coated poly aryl-ether-ether-ketone. Biomaterials. 2010;31:8181-7.

18. Zoidis P, Papathanasiou I, Polyzois G. The Use of a Modified Poly-Ether-Ether-Ketone (PEEK) as an Alternative Framework Material for Removable Dental Prostheses. A Clinical Report. J Prosthodont. 2016;25:580-4.
19. Conserva E, Menini M, Tealdo T, Bevilacqua M, Ravera G, Pera F, et al. The use of a masticatory robot to analyze the shock absorption capacity of different restorative materials for prosthetic implants: a preliminary report. Int J Prosthodont. 2009;22:53-5.

20. Rosentritt M, Schneider-Feyrer S, Behr M, Preis V. In Vitro Shock Absorption Tests on Implant-Supported Crowns: Influence of Crown Materials and Luting Agents. Int J Oral Maxillofac Implants. 2018;33:116-22.

21. Zoidis P. The all-on-4 modified polyetheretherketone treatment approach: A clinical report. J Prosthet Dent. 2018;119:516-21.

22.. Sadig W. A comparative in vitro study on the retention and stability of implant-supported overdentures. Quintessence Int . 2009;40:313-319 .

23. Scherer MD, McGlumphy EA, Seghi RR, Campagni WV. Comparison of retention and stability of implant-retained overdentures based upon implant number and distribution. Int J Oral Maxillofac Implants . 2013;28:1619-1628.

24. Hada T, Suzuki T, Minakuchi S, Takahashi H. Reduction in maxillary complete denture deformation using framework material made by computer-aided design and manufacturing systems. J Mech Behav Biomed Mater. 2019;103:103514.

25. ELsyad MA, Soliman TA, Khalifa AK. Retention and Stability of Rigid Telescopic and Milled Bar Attachments for Implant-Supported Maxillary Overdentures: An In Vitro Study. Int J Oral Maxillofac Implants. 2018;33:e127-e33.

26. Takahashi T, Mizuno Y, Gonda T, Maeda Y. Metal reinforcement of a complete maxillary denture without a palate: a preliminary report. Int J Prosthodont. 2015;28:188-90.

27. Tokuhisa M, Matsushita Y, Koyano K: In vitro study of a mandibular implant overdenture retained with ball, magnet, or bar attachments: comparison of load transfer and denture stability. Int J Prosthodont 2003;16:128-134

28. Gonda T, Ikebe K, Dong J, et al: Effect of reinforcement on overdenture strain. J Dent Res 2007;86:667-671

29. Heckmann SM, Winter W, Meyer M, Weber HP, Wichmann MG. Overdenture attachment selection and the loading of implant and denture-bearing area. Part 1: In vivo verification of stereolithographic model. Clin Oral Implants Res. 2001;12:617-23.

30. Takahashi T, Gonda T, Mizuno Y, Fujinami Y, Maeda Y. Influence of Palatal Coverage and Implant Distribution on 
Implant Strain in Maxillary Implant Overdentures. Int J Oral Maxillofac Implants. 2016;31:e136-42.

31. Mericske-Stern R, Zarb GA. In vivo measurements of some functional aspects with mandibular fixed prostheses supported by implants. Clin Oral Implants Res. 1996; 7:153-61.

32. Porter JA, Jr., Petropoulos VC, Brunski JB. Comparison of load distribution for implant overdenture attachments. Int J Oral Maxillofac Implants. 2002;17:651-62.

33. Chun HJ, Park DN, Han CH, Heo SJ, Heo MS, Koak JY. Stress distributions in maxillary bone surrounding overdenture implants with different overdenture attachments. J Oral Rehabil. 2005;32:193-205.

34. Fanuscu MI, Caputo AA. Influence of attachment systems on load transfer of an implant-assisted maxillary overdenture. J Prosthodont. 2004;13:214-20.

35. Branemark PI, Hansson BO, Adell R, Breine U, Lindstrom $\mathrm{J}$, Hallen $\mathrm{O}$, et al. Osseointegrated implants in the treatment of the edentulous jaw. Experience from a 10-year period. Scand J Plast Reconstr Surg Suppl. 1977;16:1-132.

36. Gonda T, Dong J, Maeda Y. Stress analysis of an overdenture using the finite element method. Int $\mathrm{J}$ Prosthodont. 2013;26:340-2.

37. Suwannaroop P, Chaijareenont P, Koottathape N, Takahashi $\mathrm{H}$, Arksornnukit M. In vitro wear resistance, hardness and elastic modulus of artificial denture teeth. Dent Mater J. 2011; 30:461-8.

38. Kazokoglu FS, Akaltan F. Strain characteristics of Marburg double crown-retained implant overdentures compared with bar and ball-retained implant overdentures, with and without a rigid major connector. J Prosthet Dent. 2014;112:1416-24.

39. Misch CE. The edentulous mandible: An organized approach to implant supported overdentures in contemporary implant dentistry. In: Misch CE, Abbas HA (eds). Dental Implant Prosthetics, 3rd ed. St Louis: Mosby, 2008:293-313.

40. Takahashi T, Gonda T, Maeda Y. The influence of reinforcement on strain in maxillary complete dentures: a preliminary report. Int J Prosthodont. 2011;24:273-6.

41. Tokuhisa M, Matsushita Y, Koyano K. In vitro study of a mandibular implant overdenture retained with ball, magnet, or bar attachments: comparison of load transfer and denture stability. Int J Prosthodont. 2003;16:128-34.

42. Celik G, Uludag B. Photoelastic stress analysis of various retention mechanisms on 3-implant-retained mandibular overdentures. J Prosthet Dent. 2007;97:229-35.

43. Cekic C, Akca K, Cehreli MC. Effects of attachment design on strains around implants supporting overdentures. Quintessence Int. 2007;38:e291-7.

44. Hong HR, Pae A, Kim Y, Paek J, Kim HS, Kwon KR. Effect of implant position, angulation, and attachment height on peri-implant bone stress associated with mandibular twoimplant overdentures: a finite element analysis. Int J Oral Maxillofac Implants. 2012;27:e69-76.

45. Celik G, Uludag B. Effect of the number of supporting implants on mandibular photoelastic models with different implant-retained overdenture designs. J Prosthodont. 2014; 23:374-80. 